\section{Ventricular Assist Device-Induced Ventricular Septal Perforation}

Ryogo Hoki, MD; Noriko Kikuchi, MD, PhD;

Michiru Nomoto, MD; Hidetoshi Hattori, MD, PhD;

Yuki Ichihara, MD, PhD;

Yukiko Yamada, MD, PhD; Satoshi Saito, MD, PhD;

Shinichi Nunoda, MD, PhD;

Nobuhisa Hagiwara, MD, PhD;

Hiroshi Niinami, MD, PhD

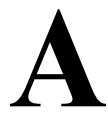

52-year-old female with refractory heart failure due to dilated cardiomyopathy underwent left ventricular assist device (LVAD; HeartMate3, Abbott, Chicago, IL, USA) implantation. One year later, transthoracic echocardiography showed restored left ventricular (LV) contraction under complete opening of the aortic valve and a reduction in LV end-diastolic diameter from $64 \mathrm{~mm}$ (preoperative) to $48 \mathrm{~mm}$ under HeartMate 3 support (estimated flow $2.7 \mathrm{~L} / \mathrm{min}$ at 4,700 r.p.m.). The LVAD was removed by the heart team of Tokyo Women's Medical University. Intraoperative transesophageal echocardiography showed no interventricular communication. The postoperative course was uneventful, although LV angiography performed before discharge revealed an unexpected de novo interventricular left-to-right shunt (Figure A; Supplementary Movie), with pooling of the contrast agent in the interventricular septum (IVS) shown by computed tomography (CT; Figure B,C). A retrospective review of CT images before removal of the LVAD indicated that part of the LVAD inflow cannula had partially pierced the apical portion of the IVS due to the extremely decreased LV (Figure D,E). The shunt ratio was 1.1 and no heart failure symptoms were noted clinically. The patient was discharged and fol- lowed up at an outpatient clinic.

We speculated that the shunt was generated because of local fragility of the IVS injured by the overhanging inflow cannula, as well as an abrupt increase in LV pressure after removal of the LVAD. These findings highlight the possibility of ventricular assist device-induced ventricular septal perforation during LVAD support in cases with an excessively small LV.

\section{Disclosures}

N.H. is a member of Circulation Journal's Editorial Team.

\section{IRB Information}

This study has been granted an exemption from requiring ethics approval by the Institutional Review Board of Tokyo Women's Medical University.

\section{Supplementary Files}

Supplementary Movie. Left ventricle angiography performed after removal of left ventricular assist device showed an interventricular left-to-right shunt near the apex.

Please find supplementary file(s);

http://dx.doi.org/10.1253/circj.CJ-21-0742

Received August 24, 2021; revised manuscript received December 10, 2021; accepted January 26, 2022; J-STAGE Advance Publication released online February 16, 2022 Time for primary review: 20 days

Department of Cardiovascular Surgery (R.H., Y.I., Y.Y., S.S., H.N.), Department of Cardiology (N.K., M.N., H.H., N.H.), Tokyo Women's Medical University, Tokyo; Department of Therapeutic Strategy for Severe Heart Failure, Graduate School of Medicine, Tokyo Women's Medical University, Tokyo (S.N.), Japan

Mailing address: Yuki Ichihara, MD, PhD, Department of Cardiovascular Surgery, Tokyo Women's Medical University, 8-1 Kawada-cho, Shinjuku-ku, Tokyo 162-8666, Japan. E-mail: ichihara.yuki@twmu.ac.jp

All rights are reserved to the Japanese Circulation Society.

For permissions, please e-mail: cj@j-circ.or.jp

ISSN-1346-9843
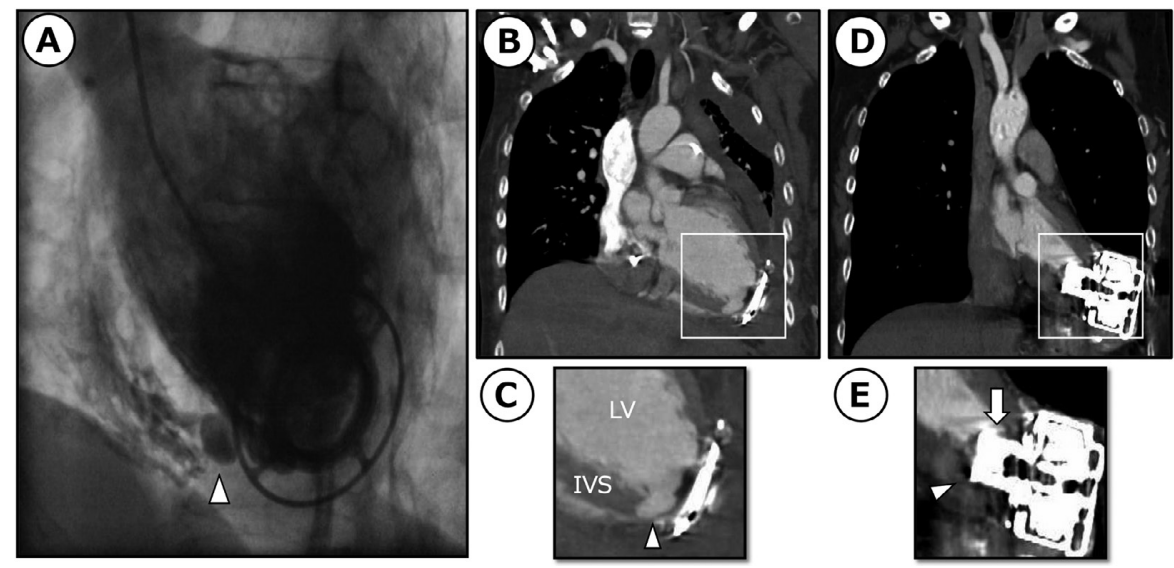

(E)

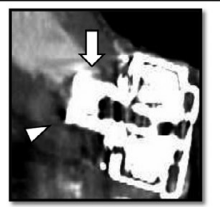

Figure. (A) Left ventricle angiography image obtained after removal of the left ventricular assist device (LVAD) showing an interventricular shunt (arrowhead). (B,C) Coronal computed tomography (CT) images after LVAD removal showing pooled contrast agent in the interventricular septum (IVS). LV, left ventricle. (D,E) Coronal CT images during LVAD support showing the inflow cannula of the LVAD (arrow) entering the IVS (arrowhead). 